\title{
Forensic patients in the emergency department: Who are they and how should we care for them?
}

Celia J. Filmalter*

celia.filmalter@up.ac.za

T. Heyns

R. Ferreira

University of Pretoria, South Africa

*Corresponding author at: Department of Nursing Science, University of Pretoria, South Africa.

The authors contributed in the conception and implementation of the study, as well as drafting, critically reviewing and preparing the manuscript.

\section{Abstract}

\section{Background}

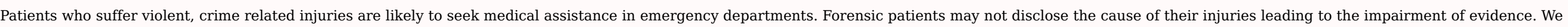
explored healthcare providers' perceptions of forensic patients and how they should be cared for.

Method

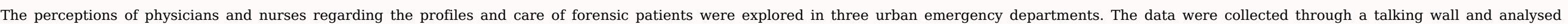
collaboratively, with the participants, using content analysis.

\section{Results}

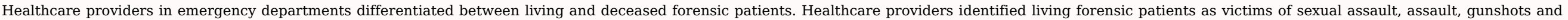

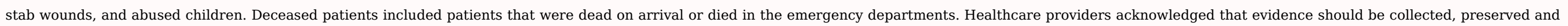
documented.

\section{Conclusion}

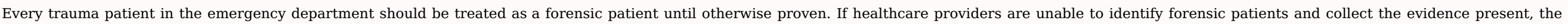
patients' human right to justice will be violated.

Keywords: Clinical forensic care; Emergency department; Violence and crime; Talking wall

\section{Introduction}

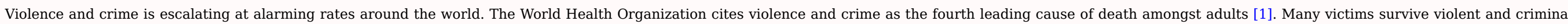

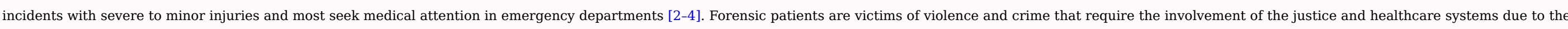
nature of their injuries [5]. Patients with traumatic injuries should therefore be treated as potential forensic patients until proven otherwise [6].

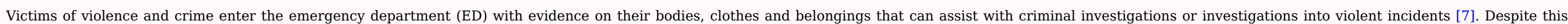

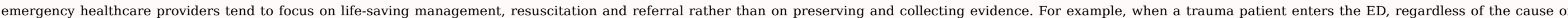

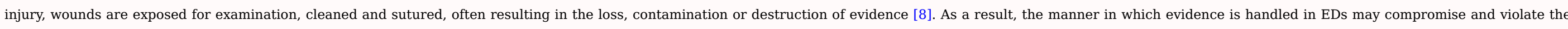




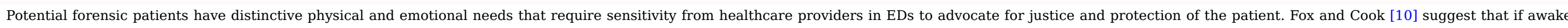

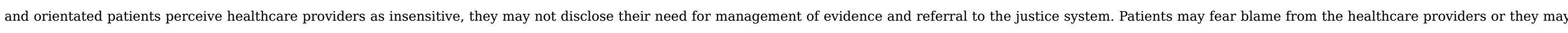

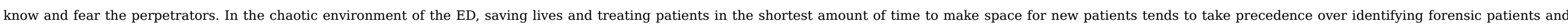

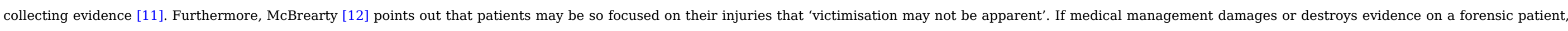

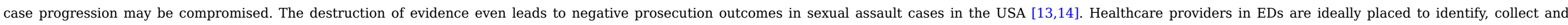
preserve evidence, and to document injuries within minutes to hours of a patient being injured.

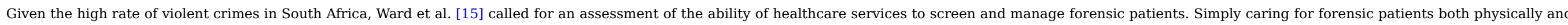

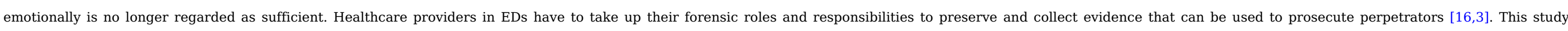

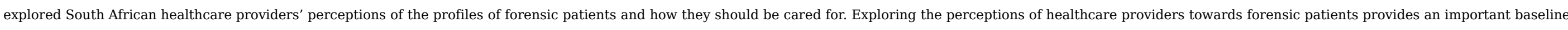
for future educational programmes and interventions aimed at simultaneous treatment of patients and collection of evidence.

\section{Methods}

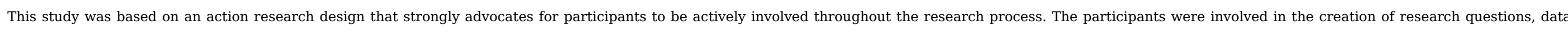

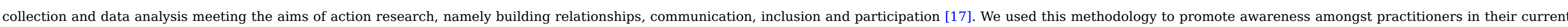
practice, encouraging them to seek solutions applicable to their context.

\subsection{Setting and sample}

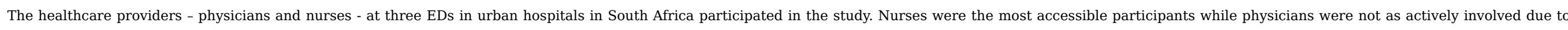

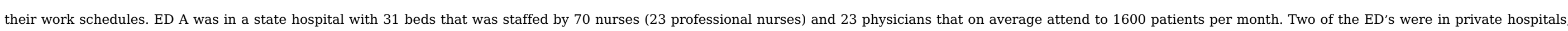

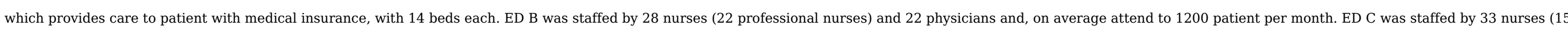

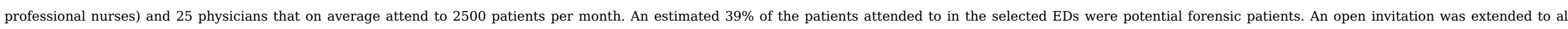
permanently employed healthcare providers to participate voluntarily. The exact number of participating healthcare providers is unknown due to the open participatory nature of the data collection method.

\subsection{Data collection}

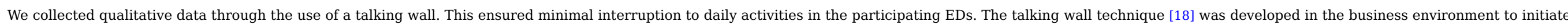

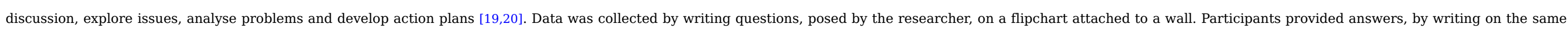
sheet of flipchart paper.

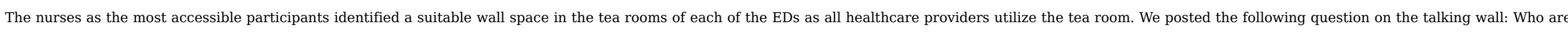

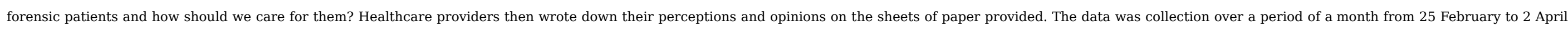

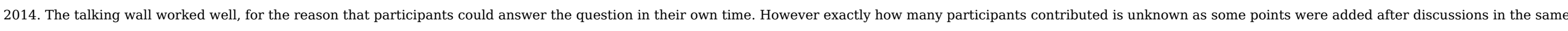
hand writing while others obscured their hand writing or just made ticks behind the point they agreed with. The answers provided was written in the form of short statements.

\subsection{Data analysis}

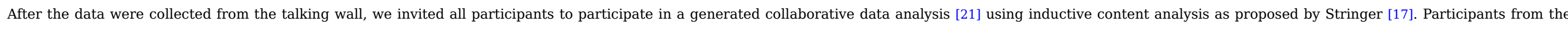

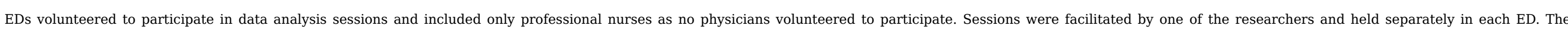

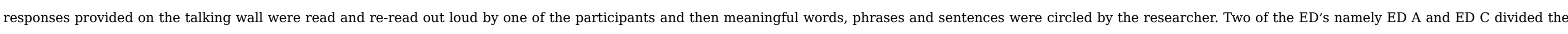

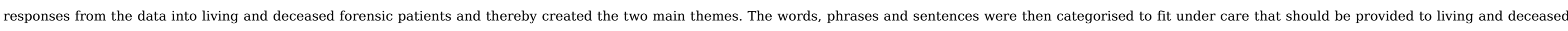
forensic patients. The data from the three EDs were combined as the categories and themes identified were similar (see Table 1 for summary) 
Table 1 Results from the collaborative qualitative content analysis.

Victims of sexual assaults

Assault victims

Gunshots victims

Victims with stab wounds

Abused children

Care rendered

Evidence collection

Preserving evidence

Documenting

Referral to the police

Gunshot

Stab wounds

Motor vehicle accidents

Pedestrians vehicle accidents

Reporting to authorities

Informing the Police

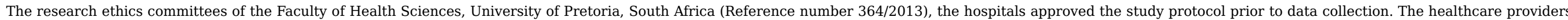
signed informed consent prior to the study and verbal process consent was obtained before each contact session.

\subsection{RIGOR}

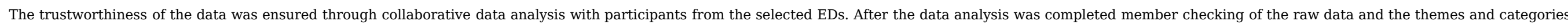

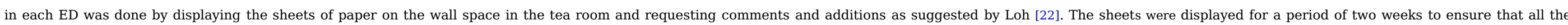
healthcare practitioners that participated had an opportunity to check the findings. No changes were made to the themes and categories.

\section{Results}

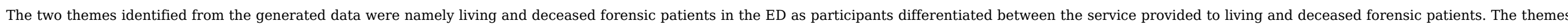
are explained using categories and excerpts from the data recorded on the talking wall as summarised in Table 1.

\subsection{Living forensic patients}

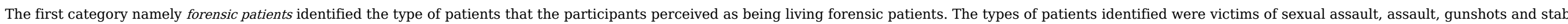
wounds, and abused children.

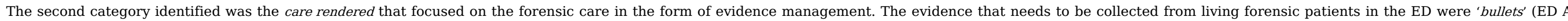

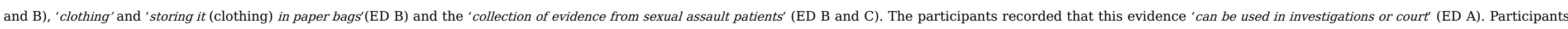

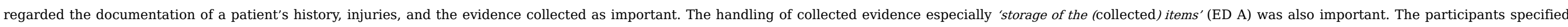




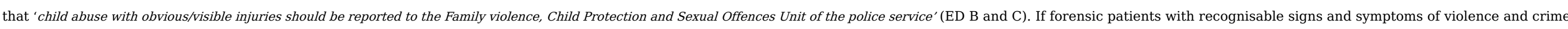
were admitted to the emergency department and found to have evidence on their person 'call the police for investigations and collection of drugs obtained from patient' (ED A).

\subsection{Deceased forensic patients}

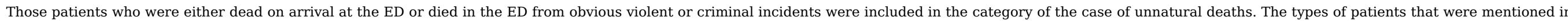
this theme included victims of gunshots, stab wounds, 'motor vehicle and pedestrian vehicle accidents' (ED B).

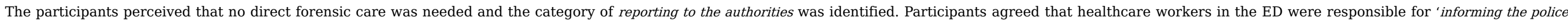
services of a patients dead on arrival' (ED B) and 'arranging post-mortems' (ED B) of deceased forensic patients.

\section{Discussion}

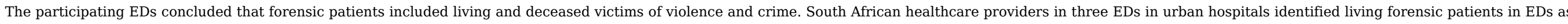

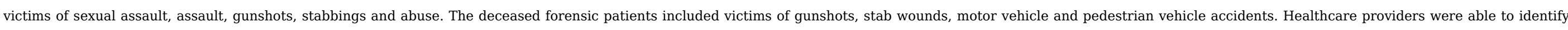
some groups of forensic patients but need to familiarize themselves with the entire forensic patient population as identified by Pasqualone [4] and Pasqualone and Michel [23,24] in Table 2.

Table 2 Categories of forensic patients.

\begin{tabular}{|c|c|}
\hline Abuse of the disabled ${ }^{*}$ & Malpractice and/or negligence \\
\hline Assault and battery* & Occupation-related injuries \\
\hline Burns $>5 \%$ of body surface area & Organ and tissue donation \\
\hline Child abuse and neglect* & Personal injuries* \\
\hline Clients in police custody & Product liability \\
\hline Control of communicable diseases & Questioned death \\
\hline Domestic violence* & Sexual assault* \\
\hline Elder abuse and neglect* & Sharp force injuries* \\
\hline End-of-life decisions -Not for resuscitation & Substance abuse \\
\hline Firearm injuries* & Toxic exposure \\
\hline Food and drug tampering & Transcultural medical practices \\
\hline Forensic psychiatric clients & Transportation injuries \\
\hline Gang violence* & Victims of mass destruction/terrorism ${ }^{*}$ \\
\hline Human and animal bites* & \\
\hline
\end{tabular}

Adapted from: Pasqualone [4] and Pasqualone and Michel [23,24]

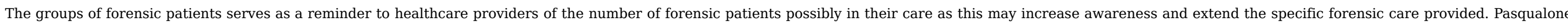

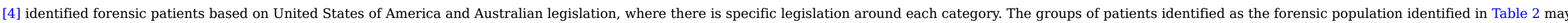

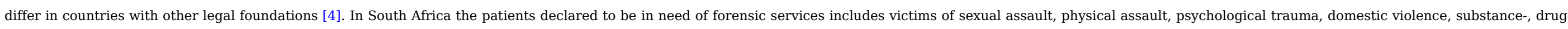

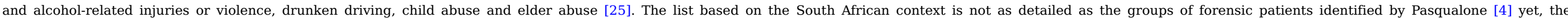



participants, further research and clarification for the omission in identifying these groups of patients is needed.

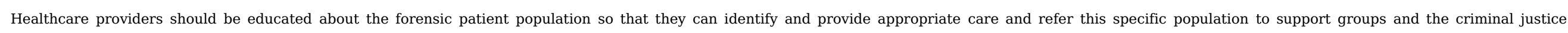

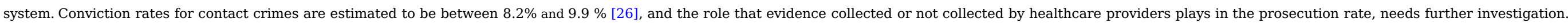

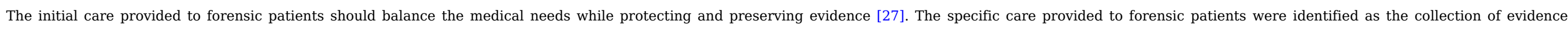

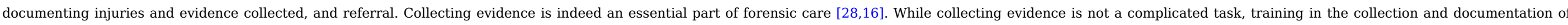

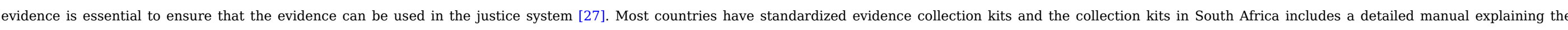

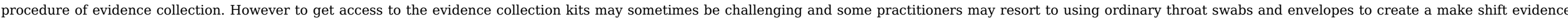

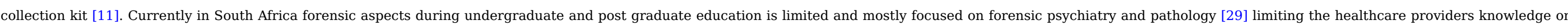

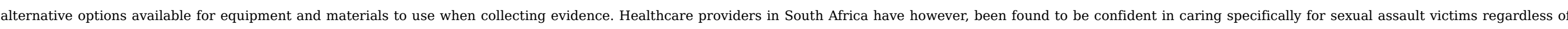

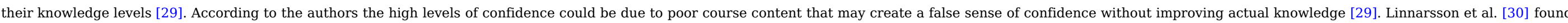

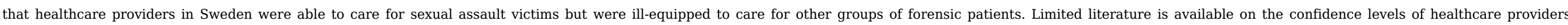
regarding forensic care and more investigation is required

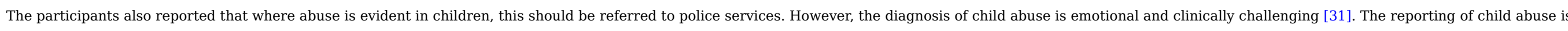
mandatory and healthcare providers in EDs are ideally placed to identify and act in order to protect the children in their care.

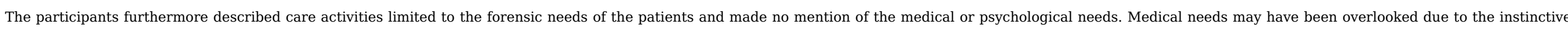

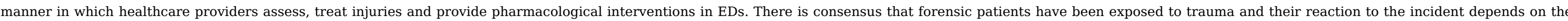

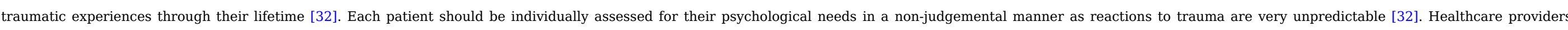

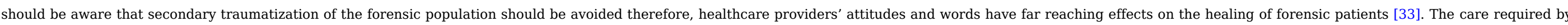
forensic patients should address their medical, forensic and psychological needs and can only be initiated after the patient has been identified as a forensic patient.

\section{Limitations}

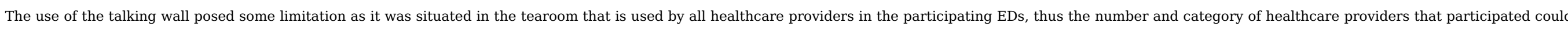

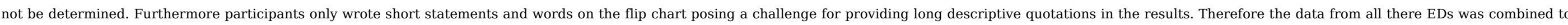
provide an overall picture of the forensic patients cared for and in what way.

\section{Recommendations}

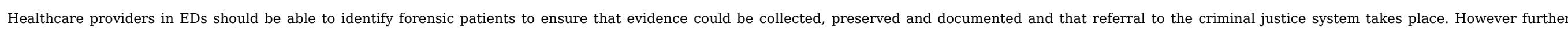

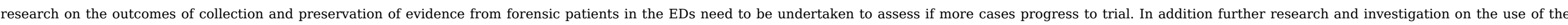
talking wall as a data collection method is needed in order to overcome the challenges.

\section{Conclusion}

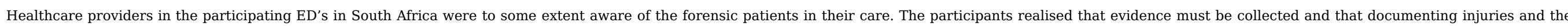

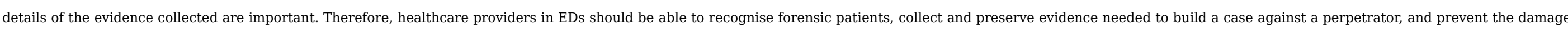
or destruction of evidence.

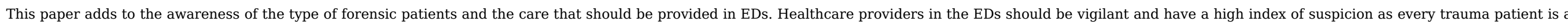
forensic patient until otherwise proven. 


\section{Conflict of interest}

We concur that we have no conflict of interest to declare.

\section{Ethical statement}

The study was approved by the Research Ethics Committee, Faculty of Health Sciences, University of Pretoria (Reference number 364/2013).

\section{Funding source}

The study was funded by: University-based Nursing Education of South Africa (UNEDSA), funded by the ELMA foundation of South Africa, for the financial support to undertake this study.

The Vice-Chancellor's Grant (University of Pretoria), which funded the educators who replaced me during my sabbatical leave.

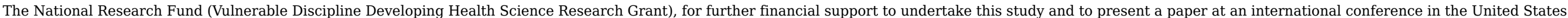

\section{References}

[1] A. Butchart and C. Mikton, Global status report on violence prevention, 2014, WHO; Geneva.

[2] A. Cucu, I. Daniel, D. Paduraru and A. Galan, Forensic Nurs Emerg Care, Rom J Leg Med 1 (22), 2014 Jun, 133-136.

[3] V.A. Lynch, Forensic nursing science: Global strategies in health and justice, Egypt J Foren Sci 1 (2), 2011 Jun 30, 69-76.

[4] G.A. Pasqualone, The Relationship between the Forensic Nurse in the Emergency Department and Law Enforcement Officials, Crit Care Nurs Q 38 (1), 2015 Jan 1, $36-48$.

[5] J.P. Wyatt, T. Squires, G. Norfolk and J. Payne-James, Oxford handbook of forensic medicine, 2011, Oxford University Press; Oxford.

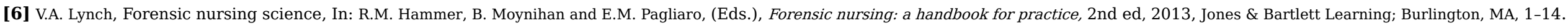

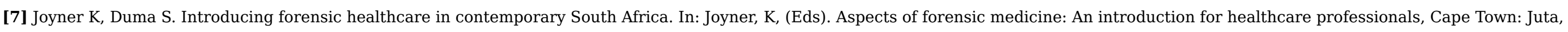
2010, p. xiv-xx.

[8] N. Çalışkan and D. Özden, The knowledge levels of health personnel in Turkey regarding forensic evidence, J Forensic Sci 57 (5), 2012 Sep 1, $1217-1221$.

[9] M.J. Johnstone, Nursing and justice as a basic human need, Nurs Philosophy 12 (1), 2011, 34-44.

[10] K.A. Fox and C.L. Cook, Is knowledge power? The effects of a victimology course on victim blaming, J Interpersonal Viol 26 (17), 2011 Nov, $3407-3427$.

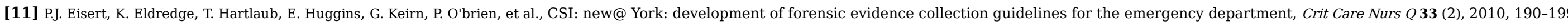
[12] P. McBrearty, The lived experience of victims of crime, Int Emerg Nurs 19 (1), 2011 Jan 31, 20-26.

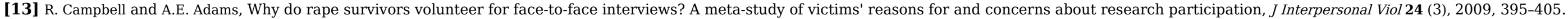

[14] K.D. Kelley and R. Campbell, Moving on or dropping out: Police processing of adult sexual assault cases, Women Criminal Justice 23 (1), 2013 Jan 1, 1-8.

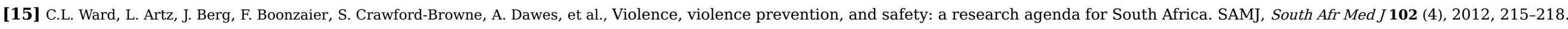

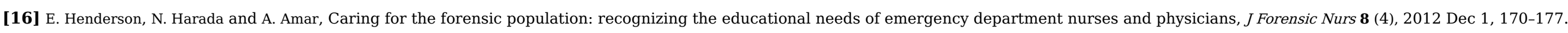

[17] E.T. Stringer, Action research, 2014, Sage Publications.

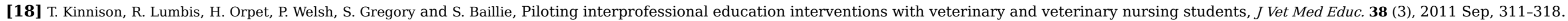

[19] R. Fruchter and P. Bosch-Sijtsema, The WALL: participatory design workspace in support of creativity, collaboration, and socialization, AI Soc 26 (3), 2011 Aug 1, 221-232 
[20] G. Parsell, T. Gibbs and J. Bligh, Three visual techniques to enhance interprofessional learning, Postgrad Med J 74 (873), 1998, 387-390.

[21] S. Flicker, Collaborative data analysis, In: D. Coghlan and C. Brydon-Miller, (Eds.), The SAGE encyclopaedia of action research, 2014, Sage; London, $121-124$.

[22] J. Loh, Inquiry into issues of trustworthiness and quality in narrative studies: A perspective, The Qualitative Rep 18 (33), 2013 Aug $19,1$.

[23] G. Pasqualone and C. Michel, Forensic patients hiding in full view, Crit Care Nurs Q 38 (1), 2015 Jan 1, 3-16.

[24] G. Pasqualone and C. Michel, Forensic patient hiding in full view, Crit Care Nurs Quart 38 (1), 2015, 3-16.

[25] South Africa. Regulations regarding the rendering of clinical forensic medicine services. Regulation 176. Pretoria: Government Printer, 2012.

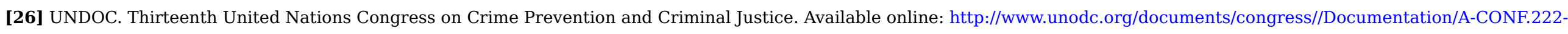
4/ACONF222_4_e_V1500369.pdf. (Accessed September 2017).

[27] L.K. Sekula, What is forensic nursing?, In: A.F. Amar and L.K. Sekula, (Eds.), A practical guide to forensic nursing, 2016, Sigma Theta Tau International; Indianapolis, 1-18.

[28] L. Starr, Assisting victims of crime-Bridging the gap from trauma to trial, Aus Nurs J ANJ The 20 (9), 2013, 29.

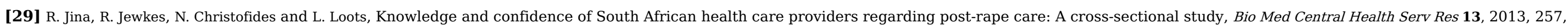
http://www.biomedcentral.com/1472-6963/13/257.

[30] J.R. Linnarsson, E. Benzein, K. Årestedt and C. Erlingsson, Preparedness to care for victims of violence and their families in emergency departments, Emerg Med J 30 (3), 2013 , $198-201$.

[31] A.N. Leetch and D. Woolridge, Emergency department evaluation of child abuse, Emerg Med Clin North Am 31 (3), 2013, 853-873.

[32] J. Valentine, L. Mabey and L. Miles, Neurobiology of trauma, In: A.F. Amar and L.K. Sekula, (Eds.), A practical guide to forensic nursing, 2016 , Sigma Theta Tau International; Indianapolis, 37-54.

[33] C. Leahy, Overarching Issues: vicarious trauma, In: B. Price and K. Maguire, (Eds.), Core curriculum for forensic nursing, 2016, Wolters Kluwer; Philadelphia, 231-252.

\section{Highlights}

- Forensic patients includes more patients that sexual assault victims.

- Nurses in emergency departments must assume their forensic responsibilities.

- A trauma patients is a forensic patient until otherwise proven. 